\title{
Diários na EJA: leitura literária de Quarto de despejo, de Carolina Maria de Jesus
}

Silmara Rodrigues"

Luciane Alves Santos"**

\section{Resumo}

Este trabalho sintetiza uma prática docente realizada com turmas de ciclo IV da Educação de Jovens e Adultos (EJA), em uma escola da rede pública da capital paraibana, em 2017. Essa proposta atendia a um requisito do Programa de Mestrado Profissional em Letras, resultando em uma dissertação de mestrado e compreendendo a realização de sequência básica de letramento literário , assim como observação e análise da produção de diários de leitura pelos estudantes . Com a pesquisa e a intervenção pedagógica em questão, buscou-se promover a leitura literária na EJA por meio de Quarto de despejo, de Carolina Maria de Jesus. O conjunto das produções dos alunos demonstrou que o exercício da escrita de diários de leitura pode desenvolver a expressão de pontos de vista mais críticos e a apreensão da linguagem literária, prezando a subjetividade leitora.

Palavras-chave: Leitura literária. Letramento literário. Diário de leitura. EJA. Quarto de despejo.

\section{Introdução}

No segundo semestre de 2017, planejamos uma intervenção pedagógica em turmas da Educação de Jovens e Adultos (EJA) de uma escola da rede municipal de João Pessoa-PB, para desenvolvimento de um processo de letramento literário. Essa intervenção foi elaborada para atender à proposta do Programa de Mestrado Profissional em Letras (Profletras), que orienta a realização de pesquisas voltadas para a prática docente no ensino fundamental das redes públicas, culminando na dissertação "Letramento literário na EJA:

\footnotetext{
Mestre em Letras pelo Programa de Mestrado Profissional da Universidade Federal da Paraíba (Profletras/ UFPB-Campus IV) em 2018. É professora efetiva de língua portuguesa da rede municipal de ensino de João Pessoa/PB, com ênfase em Teoria e Análise literária e destaque para os seguintes temas: literatura e sociedade, literatura e ensino. E-mail: rodriguessilmara@ yahoo.fr.

** Graduada em Pedagogia pela Universidade Estadual da Paraíba (UFPB). Tem experiência na área de educação. E-mail: luciane45@gmail.com.
}

Data de submissão: out. 2018 - Data de aceite: mar. 2019 http://dx.doi.org/10.5335/rdes.v15i1.8812 
uma prática com Quarto de despejo, de Carolina Maria de Jesus".

Nesse contexto, a prática se direcionou para o ciclo IV da EJA, equivalente a $8^{\circ}$ e $9^{\circ}$ anos do ensino fundamental. Trabalhamos, para isso, com o letramento literário a partir de Quarto de despejo, de Carolina Maria de Jesus, obra publicada em 1960 e na qual a escritora relata, em forma de diário, seu cotidiano como mãe solteira de três crianças e catadora de recicláveis, vivendo na Favela do Canindé, periferia de São Paulo.

Por integrar o que podemos chamar de literatura marginal/periférica ${ }^{1}$, a inscrição caroliniana no sistema literário brasileiro se apresenta como uma resistência a partir das sobreposições marginais que ela manifesta, desde sua figura autoral, representativa da escrita de mulheres, de negras e de pobres, até sua linguagem, desviante do padrão. Ademais, o fato de ser uma obra diarística permite explorar um gênero discursivo que, nas escolas, costuma carecer de representantes literários nacionais.

Em razão disso, consideramos válida a adoção de diários de leitura como forma de produção escrita para os estudantes da EJA, ao longo da leitura literária de Quarto de despejo, uma vez que dividiriam com a obra afinidades na expressão de pontos de vista críticos e reflexivos sobre temáticas ainda atuais na sociedade brasileira: mulher e trabalho, criação e educação de filhos, preconceitos racial e social, desigualdade social, condições de moradia e alimentação, dentre outros, presentes no diário caroliniano.
A experiência da leitura literária, afinal, possibilita tanto apreciar a beleza e a expressividade de uma língua quanto compreender melhor o entorno social, político, cultural etc. Todavia, fruir a leitura literária e refletir sobre ela requer planejamento para que o trabalho com a obra exceda sua concretude textual e linguística, de maneira que nos baseamos no processo de letramento literário, proposto por Rildo Cosson (2014), como recurso para favorecer a compreensão e a interpretação do texto literário na escola.

A seguir, portanto, evidenciamos os fundamentos para nossa abordagem do texto literário no ciclo IV da EJA: Quarto de despejo no contexto literário brasileiro; leitura literária e letramento literário; e diário de leitura como instrumento para o exercício da leitura reflexiva. $\mathrm{Na}$ sequência, apresentamos o percurso metodológico para a prática docente em pauta, bem como uma análise dos resultados obtidos com essa intervenção pedagógica. Por fim, trazemos nossas considerações acerca de todo o trabalho realizado.

\section{O Quarto de despejo de Carolina Maria de Jesus nas periferias do sistema literário}

No início de 1960, apareceu, nas palavras de Germana Henrique Pereira de Souza, uma "surpresa Carolina": "a favelada que escreve” (2012, p. 16). Carolina Maria de Jesus recolhia do lixo 
da cidade de São Paulo seu sustento material, pois era catadora, e também sua sobrevivência anímica, na forma de cadernos usados nos quais produzia sua literatura: poemas, letras de música, reflexões sobre seu cotidiano etc. e que, mais tarde, deram origem a Quarto de despejo, seu livro de estreia.

Escreveu sobre seu cotidiano e sobre os espaços, físicos e simbólicos, antagônicos da cidade em que vivia e, ao fazer isso, suas reflexões constituíram a forma e o conteúdo dos escritos descobertos pelo jornalista Audálio Dantas. Neles, tanto a crueza quanto a criticidade das descrições concorreram para a divulgação de Quarto de despejo como literatura de denúncia, beneficiada, ainda, pela "conjuntura de politização crescente do início dos anos 60", como afirma Luciana Paiva Coronel (2014, p. 275). Mostra dessa crueza crítica aparece logo no primeiro contato direto com a escrita caroliniana:

15 de julho de 1955 - Aniversário de minha filha Vera Eunice. Eu pretendia comprar um par de sapatos para ela. Mas o custo dos generos alimenticios nos impede a realização dos nossos desejos. Atualmente somos escravos do custo de vida. Eu achei um par de sapatos no lixo, lavei e remendei para ela calçar (JESUS, 2014, p. 11).

Nesse excerto, observamos, em paralelo, uma descrição especificamente pessoal - o par de sapatos achado no lixo para uso da filha aniversariante - e uma reflexão abrangente - o custo de vista que obriga a atender primordialmente a necessidade básica de alimentação. A mera síntese de uma conjuntura, nesse caso, consegue expressar simultaneamente uma carência pessoal da vida da escritora e uma crítica que a extrapola, ratificando Quarto de despejo como literatura de denúncia social.

Outrossim, a Favela do Canindé aparece como espaço antropomorfizado por intermédio da escrita caroliniana e onipresente na obra desde a metáfora do título até a derradeira frase: "Levantei as 5 horas e fui carregar agua" (JESUS, 2014, p. 191). Assim, esse espaço tornado personagem percorre a narrativa seja explícita - nas passagens de descrição espacial -, seja implicitamente - como presença sugerida pelo contraste com os demais espaços da cidade, por exemplo.

Observemos a evocação imagética na obra caroliniana, que resultou em construções nas quais: o espaço da cidade é quase um ser vivo - "Oh! São Paulo rainha que ostenta vaidosa a tua coroa de ouro que são os arranha-céus. Que veste viludo e seda e calça meias de algodão que é a favela" (JESUS, 2014, p. 41) -; os habitantes são extensões orgânicas dos lugares em que vivem - "Se ando suja é devido a reviravolta da vida de um favelado. Cheguei a conclusão que quem não tem de ir pro céu, não adianta olhar pra cima" (JESUS, 2014, p. 43) -; a fome ganha cor - "Que efeito surpreendente faz a comida no nosso organismo! Eu que antes de comer via o céu, as arvores, as aves tudo amarelo, depois que comi, tudo normalizou-se aos meus olhos" (JESUS, 2014, p. 44). 
Essas e outras passagens denotam literariedade por amalgamarem dois níveis de expressão de ideias: um oriundo de um âmbito mais concreto e objetivo da realidade vivida no espaço citadino - prédios e barracos, limpeza e sujeira, riqueza e pobreza, fartura e escassez etc. -, ou seja, marcado por um uso referencial da linguagem; o outro, por sua vez, provém de um âmbito mais abstrato $\mathrm{e}$ subjetivo da mesma realidade percebida pelos sentidos, mas, agora, agregando as condições de pertença e desterro ao espaço da cidade. Trata-se, nesse último caso, de um emprego metafórico da linguagem.

Em todo caso, além da caracterização de personagens e espaços, a escrita caroliniana é, igualmente, o enfrentamento de uma realidade social comumente ignorada por pessoas de condições mais privilegiadas, ou usada como demagogia por políticos. Cenas com ambos os aspectos permeiam Quarto de despejo, numa escrita abundante em desvios gramaticais, os quais Audálio Dantas (2014) manteve ao editar o livro, como explica no prefácio da obra. Não podemos ignorar, por isso, que a escrita caroliniana manifesta muitas das desigualdades estruturantes da sociedade brasileira, dentre elas a expressão de uma norma gramatical padrão da língua portuguesa.

Podemos, assim, comparar a valorização de determinadas obras literárias - não a partir da linguagem utilizada, mas sim da autoria a quem essa linguagem é atribuída - com a valorização de determinadas variedades dialetais do português brasileiro, pois, como explica Sírio Possenti, "quanto menos valor social (isto é, prestígio) têm os falantes na escala social, menos valor tem o dialeto que falam" (1996, p. 28). Essa parece ser a condição de Carolina: desvalorizada socialmente, seu dialeto passa a também carecer de valor, fechando-se, desse modo, o ciclo de (des)legitimação de sua escrita em relação às particularidades linguísticas e temáticas, como também expõe Coronel:

É possível, então, entender a literariedade como juízo de valor atribuído a um texto pelos sujeitos sociais investidos de autoridade para fazer essa definição, críticos acadêmicos, editores, jornalistas. Estes apresentaram Quarto de despejo como obra feita por uma favelada que escrevia, não por uma escritora. E favelada, segundo a visão corrente, só podia falar sobre favela, assunto que reconhecidamente conhece. Como se o bairro pobre de onde vinha empobrecesse-lhe a escrita, comprometendo sua ficcionalidade. Como se da mulher pobre não se pudesse esperar mais do que o testemunho real da pobreza. Como se seu chão fosse seu teto em termos de alcance literário (CORONEL, 2014, p. 276).

Dessa forma, a literariedade da escrita caroliniana apareceria como ocorrência fortuita, irrompendo, aleatoriamente, em meio à denúncia social da obra. Podemos, ainda, recuperar a noção de valor pontuada por Marcia Abreu, afinal, como a própria autora explica ao abordar a Grande ou Alta Literatura, há os textos "que interessam" e aqueles "em que também se encontram características literárias, mas que não se quer valorizar. Para esses, reservam-se outras 
expressões: literatura popular, literatura infantil, literatura feminina, literatura marginal..." (2006, p. 40, destaques da autora).

Produz-se, assim, um universo literário cujo centro é formado pela Grande ou Alta Literatura, isto é, o cânone. Logo, canônicos são autores e obras assim considerados por figuras e instituições legitimadoras, como críticos, universidades, professores, publicações da área etc. Tais "instâncias legitimadoras", como as chama Abreu (2006, p. 40), validam determinados textos como literários, canonizando alguns deles.

A existência de Carolina Maria de Jesus na cena literária brasileira evidencia a ordenação desse sistema, pois expõe a circunscrição de espaços tornados convencionais para alguém com suas características: o espaço doméstico, logo, privado; o secundário, então, prescindível; e o subalterno, portanto, inferior. Assim, a inscrição caroliniana no sistema literário realizaria um triplo enfrentamento: o de mulher e de negra, como ressalta Regina Dalcastagnè (2014, p. 299), mas complementamos, igualmente, o de pobre.

Carolina Maria de Jesus esteve sempre deslocada do centro literário e suas intersecções marginais fazem dela uma precursora da literatura marginal/periférica. Em todo caso, a crítica literária começa a promover uma problematização e reavaliação do cânone literário na medida em que resgata textos não legitimados por ele, conforme destaca
Graça Paulino ao recuperar o panorama da teoria crítica que, influenciada pelos Estudos Culturais, principalmente a partir dos anos 1970, "trabalhou no sentido de valorizar as camadas e os grupos sociais perseguidos ou discriminados" (2004, p. 47-48).

Em 2002, por exemplo, no capítulo "A escrita e os excluídos" da obra cujo sugestivo título é Literatura e resistência, Alfredo Bosi menciona Carolina Maria de Jesus e Quarto de despejo como destaques excepcionais no contexto literário brasileiro (2002, p. 261). Aliada à renovação desse olhar sobre à literatura, portanto, cabe também à escola abordar obras que problematizem o cânone literário brasileiro e que destoem das tradicionais representatividades linguística, socioeconômica, étnico-racial etc.

\section{Literatura, leitura literária e letramento literário}

A realidade da EJA, caracterizada por constitutivas especificidades ${ }^{2}$, costuma ser mais afetada que a do ensino fundamental "regular" no que diz respeito ao trabalho com literatura. Se, por um lado, a quantidade de estudantes - às vezes consideravelmente menor em relação aos níveis "regulares" de ensino - é um facilitador para a aquisição de exemplares de obras originais e/ou xerocopiadas, por outro, a inconstância no acompanhamento das aulas e o período dedicado a elas - geralmente apenas o noturno, e 
com hora-aula de duração reduzida em comparação com matutino e vespertino acentuam os obstáculos para a efetivação da leitura literária em sala de aula.

Ainda assim, é necessário investir na prática, pois conforme argumenta Marisa Lajolo, “[...] o cidadão, para exercer plenamente sua cidadania, precisa apossar-se da linguagem literária, alfabetizar-se nela, tornar-se seu usuário competente, mesmo que nunca vá escrever um livro: mas porque precisa ler muitos." (1993, p. 106). A alfabetização na linguagem literária é também função da escola, posto ser essa instituição "a mais importante agência de letramento da sociedade", empregando as palavras de Ângela Kleiman (2005, p. 38). Mas, além disso, sendo a escola um espaço no qual profissionais da educação, estudantes e variadas formas de conhecimento já interatuam, a literatura pode ser apreciada simplesmente por engendrar, artisticamente, formas de expressão para a linguagem, como explica Irandé Antunes:

Ler textos literários possibilita-nos o contato com a arte da palavra, com o prazer estético da criação artística, com a beleza gratuita da ficção, da fantasia e do sonho, expressos por um jeito de falar tão singular, tão carregado de originalidade e beleza. Leitura que deve acontecer simplesmente pelo prazer de fazê-lo. Pelo prazer da apreciação, e mais nada. Para entrar no mistério, na transcendência, em mundos de ficção, em cenários de outras imagens, criadas pela polivalência de sentido das palavras (ANTUNES, 2009, p. 200).

O prazer estético e a expressividade da linguagem a que se refere Antunes, somados ao fator de cidadania apontado por Lajolo, fazem da literatura uma potência criadora e socializadora da linguagem, possibilitando desenvolvimento intelectivo, subjetivo e cultural. Não por acaso, Antonio Candido a defende como um direito do ser humano, definindo-a como "todas as criações de toque poético, ficcional ou dramático em todos os níveis de uma sociedade, em todos os tipos de cultura, desde o que chamamos folclore, lenda, chiste, até as formas mais complexas e difíceis da produção escrita das grandes civilizações." (2011, p. 176).

O autor conclui que não há sociedade sem manifestação literária. Dessa forma, segundo Candido, se para ninguém é possível viver sem se entregar a um universo ficcional e poético, a literatura não apenas é uma necessidade que precisa ser satisfeita, como também confere ao ser humano sua própria humanidade. Em razão disso, atribui à literatura uma função humanizante, explicando como a compreende:

Entendo aqui por humanização (já que tenho falado tanto nela) o processo que confirma no homem aqueles traços que reputamos essenciais, como o exercício da reflexão, a aquisição do saber, a boa disposição para com o próximo, o afinamento das emoções, a capacidade de penetrar nos problemas da vida, o senso da beleza, a percepção da complexidade do mundo e dos seres, o cultivo do humor. A literatura desenvolve em nós a quota de humanidade na medida em que nos torna mais compreensivos e abertos para a natureza, a sociedade, o semelhante (CANDIDO, 2011, p. 182).

Compreendida dessa maneira, a literatura tem parte fundamental na 
constituição da personalidade humana e, consequentemente, sua fruição torna não apenas a pessoa mais humanizada, mas também a sociedade. Afinal, a leitura literária pode promover a ampliação da consciência acerca de quem somos e de como é o mundo em que vivemos, sendo o processo orientado para a apreensão da linguagem literária na escola chamado de letramento literário. De acordo com Graça Paulino, o letramento literário insere o sujeito no universo de produção e recepção de textos literários, tendo em vista que

[...] um cidadão literariamente letrado seria aquele que cultivasse e assumisse como parte de sua vida a leitura desses textos, preservando seu caráter estético, aceitando o pacto [ficcional] proposto e resgatando objetivos culturais em sentido mais amplo, e não objetivos funcionais ou imediatos para seu ato de ler (PAULINO, 2001, p. 117-118).

Afim com o raciocínio de Candido quanto ao direito à literatura, Paulino justifica o letramento literário nas escolas como uma forma de fomentar a democratização de recursos materiais, simbólicos e intelectuais com vistas à garantia de inclusão social, uma vez que a apreciação da arte em geral, e da literatura em particular, não deve ser tratada como privilégio em uma sociedade democrática (2001, p. 118).

Atentamos, então, para a importância de a escola, sobretudo a pública, estimular a leitura literária como uma prática cultural possível de exceder o ambiente e a época de escolarização. Para tanto, os propositores da leitura literária na sala de aula, ou seja, os professores, precisam conhecer a natureza do texto literário e se instruir bem para o trabalho com ele. Nesse sentido, Rildo Cosson apresenta três tipos de aprendizagens que compreendem a literatura: aprendizagem da literatura; aprendizagem sobre a literatura; e aprendizagem por meio da literatura (2014).

Dessa tríade, segundo Cosson, as aprendizagens sobre e por meio da literatura fazem parte da tradição de atividades escolares com textos literários, concentrando-se, respectivamente, na aquisição de conhecimentos históricos, teóricos e críticos, e na apreensão de saberes pela prática da leitura literária (2014, p. 47). Já a aprendizagem $d a$ literatura é negligenciada, justamente a que "deveria ser o ponto central das atividades envolvendo literatura na escola" (COSSON, 2014, p. 47), uma vez que compreende a experiência direta com a linguagem literária durante a leitura de textos do gênero.

Trata-se de uma experiência pessoal que, por isso mesmo, não pode ser delegada a ninguém que ao próprio sujeito leitor. No entanto, como o tratamento convencional do texto literário na escola, orientado por uma leitura de tipo apli$c a d a^{3}$, não vem apresentando resultados satisfatórios para a formação leitora, o letramento literário e seu pressuposto de fruição passaram a nortear novos modos de trabalho com o texto literário, estendendo a leitura de tipo ilustrada para além dos anos iniciais do ensino fundamental. 
A concretização do processo de letramento literário, por sua vez, parte de uma sistematização da leitura por meio de sequência de atividades, nomeada por Cosson (2014) como sequência básica e que contempla: motivação (conquista da atenção para a leitura do texto literário); introdução (apresentação sucinta da autoria e da obra); leitura (leitura literária propriamente dita, isto é, contato direto do leitor com o texto); intervalos (atividades com textos complementares ao texto literário principal); e interpretação (construção e socialização de sentidos sobre o texto).

Cosson (2014) ressalta, ainda, que as possibilidades de criação de sequências não se esgotam nos exemplos trazidos por ele. Pelo contrário, o professor tem total liberdade de adaptá-las, reformulá-las ou recriá-las para atender à realidade e à necessidade de seus estudantes e de sua escola, pois é ele o conhecedor de sua turma, dos recursos de que dispõe para as atividades de leitura literária, e dos objetivos que pretende atingir com o texto literário selecionado. Nossa proposta de trabalho, nesse sentido, partiu de uma sequência básica de letramento literário para a leitura de Quarto de despejo e para a produção de diários de leitura como forma de registro.

\section{Diários de leitura}

O letramento literário demanda atividades nos momentos anterior, concomitante e posterior à leitura - simplificada- mente, podemos afirmar que a motivação e a introdução antecedem a leitura; a leitura, obviamente, é o momento e a atividade em si; enquanto a interpretação pode ser tanto concomitante quanto subsequente a ela. Os diários de leitura produzidos pelo ciclo IV da EJA se configuraram, nesse sentido, como uma forma de registro da interpretação, durante e após a leitura.

A escrita de diários de leitura possibilita que os estudantes extrapolem a leitura mecânica e literal, aprofundando a compreensão sobre temas e comportamentos, e se engajando de forma mais pessoal e crítica na interação com o texto. Nessa perspectiva, Anna Rachel Machado define o diário de leitura como um artefato ou instrumento muito útil para a leitura reflexiva:

Podemos dizer, em um primeiro momento, que o diário de leituras é um texto produzido por um leitor, à medida em que lê, com o objetivo maior de dialogar, de "conversar" com o autor do texto, de forma reflexiva. Para produzi-lo, o leitor deve se colocar no papel de quem está em uma conversa real com o autor, realizando operações e atos de linguagem que habitualmente realizamos quando nos encontramos nessa situação de interação (MACHADO, 2005, p. 64).

A escrita de diários de leitura, portanto, se constitui como uma prática dialógica entre estudante leitor e texto lido, estabelecendo uma "conversa real com o autor" (MACHADO, 2005, p. 64). Tal aspecto, aliás, deve ser evidenciado para os estudantes, ressaltam Machado e também Marina Gonçalves Buzzo (2010), assim como o fato de que o diário 
de leitura, na escola, é uma produção para ser compartilhada e discutida pelos envolvidos no processo de ensino-aprendizagem dessa atividade: professor e alunos.

Quanto a esse aspecto, precisa-se considerar que não é sem esforço que se instaura a socialização de escritos individuais na sala de aula. Afinal, como pontua Annie Rouxel em seu trabalho sobre a expressão do sujeito leitor, precisa-se incentivar "abordagens sensíveis das obras", considerando tanto os modos pelos quais os estudantes recebem as obras quanto o que optam por exteriorizar de sua "experiência estética". Segundo a autora, ainda, os estudantes têm plena consciência de que se revelam ao discutirem as obras, por isso, "a dimensão social da leitura escolar pode ser um entrave à palavra dos alunos" (2012, p. 281).

Nesse sentido, com o exercício de registrar por escrito as impressões sobre um texto, no caso literário, estimamos também o desenvolvimento de uma postura ativa e autoconfiante diante da leitura e das próprias opiniões. Acompanhamos, nesse aspecto, a trilha aberta pelas pesquisas de Machado (2018), buscando trabalhar para "despertar a voz do aluno" por meio da elaboração e apreciação de diários de leitura.

Esse despertar pode ser estimulado por uma leitura cursiva, que se configura como uma dimensão de liberdade para a expressão subjetiva do leitor, como a define Rouxel: "Leitura autônoma e pessoal, ela autoriza o fenômeno da iden- tificação e convida a uma apropriação singular das obras. Favorecendo outra relação com o texto, significa um desejo de levar em conta os leitores reais" (2012, p. 276). Dessa forma, o diário de leitura é, seguindo o pensamento de Rouxel, uma escrita de invenção, pois "entreabre uma porta à expressão do sujeito" (2012, p. 276).

Todavia, assim como o letramento literário discutido por Cosson (2014) precisa ser motivado e planejado de modo a engajar os alunos na leitura literária, da mesma maneira, a produção de diários de leitura exige um desenvolvimento que os incentive à escrita. Sobretudo essa escrita de caráter crítico e reflexivo, que buscamos fazer prosperar, mas que, dada a sua evidente complexidade na organização de conhecimentos, nos parece pouco estimulada nas aulas de língua portuguesa.

O desafio cresce, também, por sabermos que a característica heterogeneidade dos estudantes da EJA coloca os professores diante de poucos leitores fluentes e de outros semialfabetizados, de alunos com horário flexível para a realização de tarefas e de outros para quem a escola já se apresenta como um terceiro "turno de trabalho". Em todo caso, consideramos o diário de leitura como um instrumento para motivar a leitura e a escrita reflexiva desses estudantes. De acordo com Buzzo, citando Colette Buguet-Melançon: 
Certamente, alguns alunos podem ser considerados bons leitores e pouquíssimos considerados excelentes, entre uma grande maioria que sequer atinge o primeiro nível de leitura, o da observação e compreensão de informações explícitas. Apesar dessa heterogeneidade, os alunos precisam aprender a ler textos de diferentes gêneros, inclusive os literários, pois esse exercício pode contribuir para que os alunos com mais dificuldades tenham acesso aos conhecimentos. Nessa perspectiva, a prática diarista pode responder a esse desafio, se o aluno for capaz de se responsabilizar pela própria construção do sentido do texto, mobilizando seus conhecimentos linguísticos e gerais e suas estratégias de leitura (BUGUET-MELANÇON, 1997 apud BUZZO, 2010, p. 16-17).

Assumimos, especialmente, a possibilidade de trabalho com o texto literário para aprimorar a capacidade crítica e ampliar a aquisição de conhecimentos, pois entendemos que, com a prática do diário de leitura, os estudantes podem exercitar o posicionamento crítico diante dos textos, colocando-se como leitores ativos, como afirma Buzzo: “[...] o diário de leitura permite ao leitor ultrapassar os limites da compreensão, ao tecer comentários, a relacionar o texto lido com conhecimentos prévios, superando em todos os sentidos as atividades de leitura que vêm sendo oferecidas na escola" (2010, p. 17).

Por essa razão, retomamos mais uma vez Rouxel para ressaltar que o diário de leitura possibilita vislumbrar "o investimento subjetivo do leitor", uma vez que a subjetividade constitui aspecto indissociável da leitura literária, pois "é o leitor que completa o texto e lhe imprime sua forma singular" (2012, p. 278). A autora propõe, então, uma forma de ensejar a subjetividade leitora nos textos na prática escolar:

É possível modificar a relação com o texto construído por meio da leitura escolar desenvolvendo uma "didática da implicação" do sujeito leitor na obra. Para isso, convém incentivar a expressão do julgamento estético, convidando o aluno a se exprimir sobre seu prazer ou desprazer em relação à leitura, evitando censurar os eventuais traços, em seu discurso, de um investimento por demais pessoal, imaginário e fantasmático. Não se trata, portanto, de renunciar ao estudo da obra em sua dimensão formal e objetivável, mas de acolher os afetos dos alunos e de incentivá-los na descoberta de dilemas pessoais na leitura (ROUXEL, 2012, p. 281).

Para observarmos tal "implicação do sujeito leitor na obra”, precisamos de indícios na escrita dos estudantes. Buscamos, então, reanimar a subjetividade do leitor na experiência da leitura literária, acompanhando a argumentação de Gérard Langlade, segundo a qual a atividade leitora participativa institui um "investimento emocional, psicológico moral e estético [que] inscrevem a obra como uma experiência singular" (2013, p. 36-37). Encontramos parte desse investimento por meio de "ecos íntimos", "marcas de subjetividade" linguisticamente empregadas na escrita.

O diário de leitura foi adotado, então, para que os estudantes registrassem as impressões suscitadas pela leitura da Quarto de despejo, que nos beneficiou com uma escrita em forma de diário, constituindo certa proximidade com um diário de leitura. Ademais, essa forma de registro se configura, também, como um 
recurso para que nós, professores, possamos refletir sobre a efetividade de nossa prática, pois, a partir das reflexões que os estudantes escolhem compartilhar, podemos examinar as propostas de atividades e, quando for o caso, fazer as reformulações metodológicas necessárias.

\section{Procedimento metodológico para a leitura literária e a produção de diários de leitura}

A proposta de intervenção pedagógica completa foi realizada em 30 horas-aulas, ou cerca de seis semanas de aula na EJA, modalidade cuja carga horária é reduzida em relação ao ensino fundamental "regular". Além disso, o processo de letramento literário se deu em torno de uma obra extensa, considerando o padrão dos textos literários trabalhados nas aulas de língua portuguesa. Todavia, como este trabalho se concentra na leitura literária de Quarto de despejo para a produção de diários de leitura, apenas sintetizamos as etapas da sequência básica do processo de letramento literário realizado com o ciclo IV da EJA:

- Motivação: leitura e audição da canção "Comida", dos Titãs, a fim de explorar as condições de acesso à alimentação e sua qualidade na sociedade brasileira.

- Introdução: distribuição de exemplares de Quarto de despejo para contato direto com a obra física; e apresentação resumida sobre a vida de Carolina Maria de Jesus, suas obras em geral, e Quarto de despejo em particular.

- Leitura: leitura compartilhada, em sala, de trechos selecionados da obra; e leitura extraclasse, de acordo com as possibilidades de cada estudante.

- Intervalo: leitura, em sala, de textos complementares; e atividades, em sala, sobre os textos complementares, incluindo a escrita de diários de leitura.

- Interpretação: escrita, em sala ou extraclasse, dos diários de leitura; socialização voluntária dos diários e de reflexão sobre a leitura de Quarto de despejo.

Os dois primeiros momentos foram realizados em poucas horas-aula. Já as etapas de leitura, intervalo e escrita dos diários de leitura constituíram uma espécie de ponto médio do processo de letramento literário, ocupando mais horas-aula e organizadas ciclicamente. $\mathrm{Na}$ etapa de leitura, uma hora-aula por semana foi dedicada à leitura de trechos da obra, posto que os livros ficaram à disposição dos estudantes para a continuidade da leitura em momentos extraclasse.

Em geral, as leituras em voz alta foram feitas pela professora, exceto nas ocasiões em que algum estudante se dispunha a fazê-las. A dinâmica para a leitura consistiu, na maioria das aulas, na formação de uma roda de leitura, 
formato que gradativamente se tornou um hábito para a atividade. Também foram trabalhados textos complementares, selecionados a partir de correlações temáticas com Quarto de despejo e com atenção especial para a diversidade de gêneros e tipos textuais, incluindo obras audiovisuais e imagéticas: "Ilha das Flores", curta-documentário de Jorge Furtado; "O bicho", poema de Manuel Bandeira; "Morro da Favela", óleo sobre tela de Tarsila do Amaral; e "Vozes-mulheres", poema de Conceição Evaristo.

Finalmente, na etapa de produção dos diários de leitura, foi explicado aos estudantes que cada um produziria três escritas sobre Quarto de despejo, podendo comentar as informações que julgassem pertinentes: impressões sobre a história narrada e a escritora, trechos que tivessem lhes chamado a atenção, outras obras recuperadas pela memória, experiências pessoais, comentários sobre a situação social atual ou passada etc. Para cada produção nos diários de leitura, os estudantes receberam um conjunto de orientações que os auxiliasse na escrita, posto ser corrente, no ciclo IV da EJA, a queixa em torno de dificuldades para "começar a escrever".

Essas orientações compreendiam as seguintes indicações: primeiro, uma instrução sobre a atividade (Escrever um comentário com suas impressões sobre Quarto de despejo, na forma de diário de leitura. Para isso, é importante expor pontos de vista que estão sendo desenvolvidos a partir da leitura da obra e das atividades realizadas nas aulas.); depois, quatro sugestões sobre possíveis conteúdos para os registros (comentar tanto o que conseguiu compreender quanto às dúvidas surgidas com a leitura; comentar sobre seus pensamentos, sua vida, a escola, a sociedade, o mundo etc.; relacionar Quarto de despejo com um texto complementar trabalhado em aula, ou com outras obras - livros, músicas, filmes etc. - que conhecer; transcrever trechos de Quarto de despejo ou de qualquer outra obra sobre a qual queira falar para usar como exemplos para seus comentários).

Muitos estudantes fizeram os diários de leitura em sala de aula, pois o alunado da EJAé, geralmente, formado por mães e pais de família, e mesmo por jovens já no mundo do trabalho, cujo tempo destinado aos estudos, por vezes, se resume ao horário de aula. Ainda assim, houve quem os realizasse em tempos extraclasse, alternativa assegurada desde 0 princípio. Dessa forma, apesar de nem todos os estudantes terem feito as três escritas, foram produzidos trinta e nove registros no total.

Para a análise das produções, acompanhamos o traçado metodológico sugerido por Romeu Gomes (2009), ou seja, realizamos a leitura do material, a fim de apreendermos uma noção do conjunto, bem como de suas particularidades. Em seguida, delineamos formas de classificação do material e norteadores para análise e interpretação dos dados. Com base nisso, organizamos três grupos: i) trabalhos realizados como atividades de intervalo, a partir dos textos complementares; ii) diários de leitura dos estudantes; iii) produções obtidas pela 
sondagem de conhecimentos ao início e ao término do processo de letramento literário. Concentramo-nos, aqui, tão somente nos diários de leitura.

\section{Resultados e análise}

Tendo em vista que a maior parte dos estudantes adotou as orientações para registro no diário de leitura como uma espécie de guia para a escrita, consideramos as orientações sugeridas como entradas de análise da apreensão da linguagem literária e da manifestação de apreciação crítica e reflexiva acerca da obra. Dessa forma, elaboramos uma classificação com três níveis de atendimento às orientações, de acordo com o desenvolvimento da reflexão transposta para a escrita: i) atendimento pleno, quando o comentário escrito explora justificativas ou possibilidades interpretativas; ii) atendimento parcial, quando o comentário introduz alguma observação, mas não a desenvolve; iii) não desenvolvimento, quando não há menção ao tópico da orientação. Passemos, então, à análise dessas orientações, observando trechos dos diários de leitura produzidos.

A primeira orientação - "comentar tanto o que conseguiu compreender quanto as dúvidas surgidas com a leitura" - demanda do sujeito leitor o exercício de construção de sentidos para o texto, recuperando passagens, bem como de dúvidas surgidas com a leitura. O objetivo foi o de estimular uma postura ativa e reflexiva durante $o$ ato de ler, dado que os estudantes precisariam explicar passagens e panoramas mais abrangentes da narrativa. Como consequência, a releitura para confirmação e/ou modificação do fazer interpretativo era também incentivada. Observemos um trecho ${ }^{4}$ de diário de leitura que exemplifica o nível de atendimento parcial a essa orientação, na Figura 1, a seguir:

Figura 1 - Produção B3 correspondente ao nível de atendimento na primeira orientação

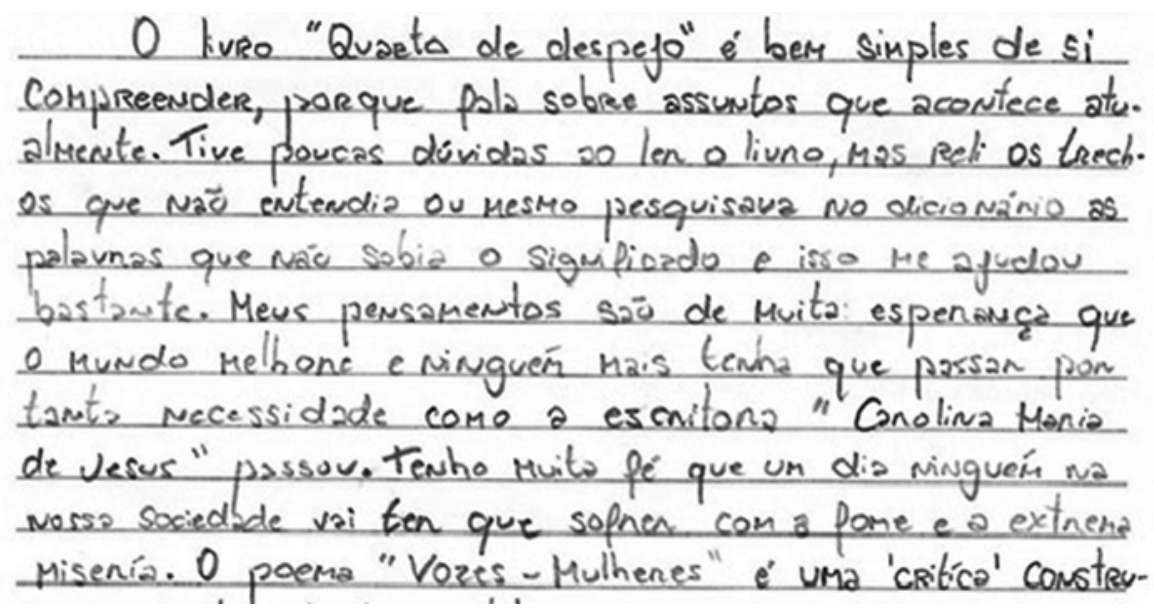

Fonte: Arquivo da professora de Língua Portuguesa do ciclo IV da EJA. 
Em B3, a orientação é atendida parcialmente, visto que a exposição da compreensão - "é bem simples de si compreender, porque fala sobre assuntos que acontece atualmente" - e da dúvida - releitura e consulta ao dicionário - não são desenvolvidas, os assuntos atuais e as palavras desconhecidas jamais são mencionados. Sabemos, pela afirmação, que houve compreensão e dúvidas, mas não as conhecemos. Por ser o terceiro registro, depreendemos que B3 se posicionou de forma a expor um panorama de sua experiência de leitura, uma vez que a sequência da produção exterioriza um ponto de vista, também panorâmico, sobre o conteúdo da narrativa diarística de Carolina Maria de Jesus.

Contudo, tal sequência não deixa de ecoar subjetividade, pois "o pensamento de esperança" e a "fé" se articulam à lembrança do lido em sua significação textual - "passar por tanta necessidade como a escritora 'Carolina Maria de Jesus" - e contextual - "ninguém na nossa sociedade vai ter que sofrer com a fome e a extrema miseria". Mais uma vez, recuperamos Langlade para conjec- turar quanto à apreensão literária de B3, considerando que "o texto vive de suas ressonâncias com as lembranças, as representações íntimas de si, dos outros, do mundo do leitor" (2013, p. 31).

Por sua vez, a segunda orientação "comentar sobre seus pensamentos, sua vida, a escola, a sociedade, o mundo etc." - permite conduzir o sujeito leitor por um trajeto de dentro para fora do texto, estimulando uma reflexão que amplie os significados da leitura. Objetivamos, assim, uma experiência de leitura literária que extrapole a compreensão de "o que o texto quer dizer", efetivando a interação leitor-texto-autor que pode ser observada na expressão de saberes e vivências dos estudantes, desencadeada pela leitura.

Consideramos, nesse aspecto, "a relação pessoal com a obra lida" de que fala Rouxel ao abordar a escrita de diários de leitura: "O jovem leitor exprime suas reações diante do texto e se interroga sobre aquilo que sente" (2012, p. 276). Verifiquemos como as produções atenderam à segunda orientação, a seguir, nas Figuras 2 e 3: 
Figura 2 - Produção C2 correspondenete ao nível de atendimento na segunda orientação.

as penbamentos cleler muitas vezes era marer mais timha dias que lla cecerclava espiracea i mais pra éma mita gente tem proconblito ecom cos negros ate as perse as megras que dizque e parda mais So' lyists Branece l negro ĺsanto preeconeéto que nega sra propria eor por eausa das persoces

esbe treebra " Nás scomos palveres, vilmos para as margens do rio. as margens do rico sáo es lugares elo eíxo ldos marginar"

meabe trodro entencio que samos lixos a es elvidoes do munclo uma ecisa sem valcer auanclco a pessoa penexa iso i que sie acha lem macka i quem flz lssa situalấo poíos politieos que máo afuda mấ cläo empregas solrem Roera, 20 ser lruman tamleém por eanta ded Rasísmo - nás veja minbum eraneco messa situctér.

Fonte: Arquivo da professora de Língua Portuguesa do ciclo IV da EJA.

Começando por C2, acompanhamos a expressão de um ponto de vista político em resposta a determinado trecho de Quarto de despejo. O ponto de vista ideológico - termo que empregamos, aqui, em seu sentido lato - de C2 dialoga com uma colocação de mesmo teor da narrativa diarística de Carolina Maria de Jesus, construindo sentidos para a obra e, a partir dela, também pra seu entorno social. Dessa maneira, vislumbramos o "envolvimento simbólico" entre sujeito leitor e texto, fruto da "dimensão ética e antropológica da literatura", como afirma Rouxel (2012, p. 276). Trata-se, por isso, de uma produção que atende plenamente à segunda orientação. 
Figura 3 - Produção 11 correspondente ao nível de atendimento na segunda orientação

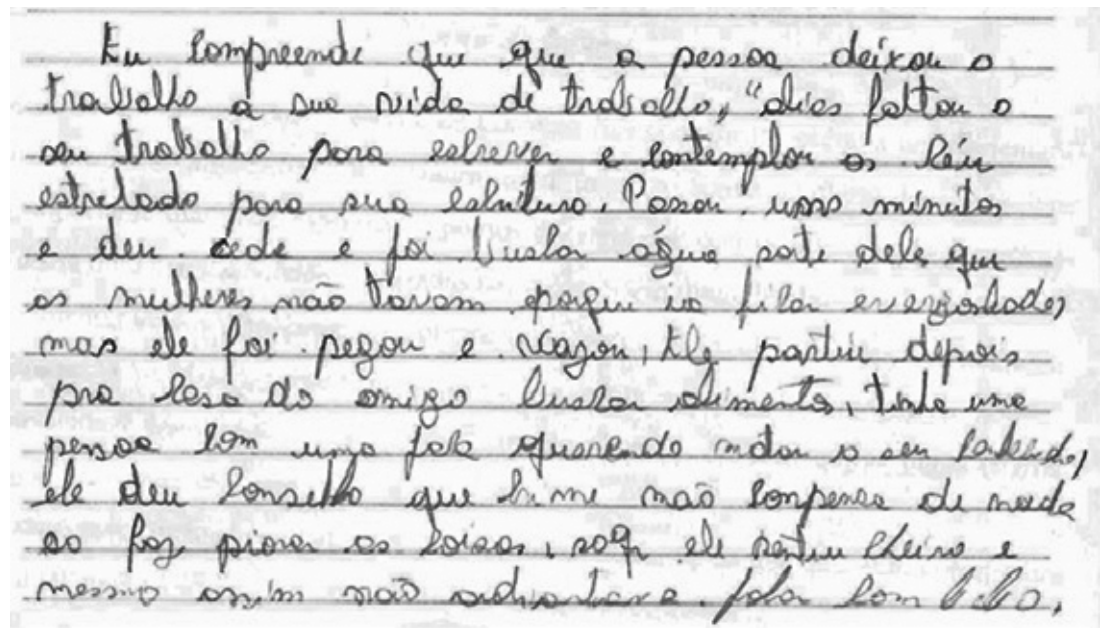

Fonte: Arquivo da professora de Língua Portuguesa do ciclo IV da EJA.

Já em I1, encontramos a exposição breve de passagens de Quarto de despejo, em que apenas certos aspectos são apresentados, mas não comentados. Consideramos, assim, que I1 corresponde ao solicitado na primeira orientação, apesar de se referir reiteradamente à protagonista como "ele", mas não na segunda. Com tais características, de fato, esse primeiro registro ainda não se qualifica como diário de leitura.

Avançando para a terceira orientação - "relacionar Quarto de despejo com outras obras (livros, músicas, filmes etc.), trabalhadas ou não em aula" -, vemos que pede ao sujeito leitor a extrapolação do texto para outros textos, estabelecendo relações de sentido que alicercem um repertório de leitura ampliado. Buscamos, a partir dessa orientação, impulsionar o exercício de comparação entre obras, chamando os estudantes a refletirem sobre as semelhanças e diferenças que conseguissem discernir.

Adotamos esse expediente não como um fim em si mesmo, senão como uma maneira de se desenvolver a interlocução entre textos, construída através de uma reflexão cuja transposição para a escrita inserisse o texto do próprio estudante e sua subjetividade no diálogo. Não que fosse descomplicado mapear essa inserção, pois a experiência da leitura, mesmo quando compartilhada, guarda uma dimensão íntima e pessoal que, conforme afirma Rouxel, "não se deixa observar" (2012, p. 277).

Em razão desse caráter inobservável, recorremos aos "marcadores de subjetividade", como os chama Langlade, na materialidade do texto. No caso da comparação, podemos observar traços do 
caminho que este exercício percorreu ao ser tornado consciente em sua transposição para a escrita. Assim, nas Figuras 4 e 5, a seguir, divisamos as formas pelas quais as produções atenderam a essa terceira orientação:

Figura 4 - Produção O3 correspondente ao nível de atendimento na terceira orientação.

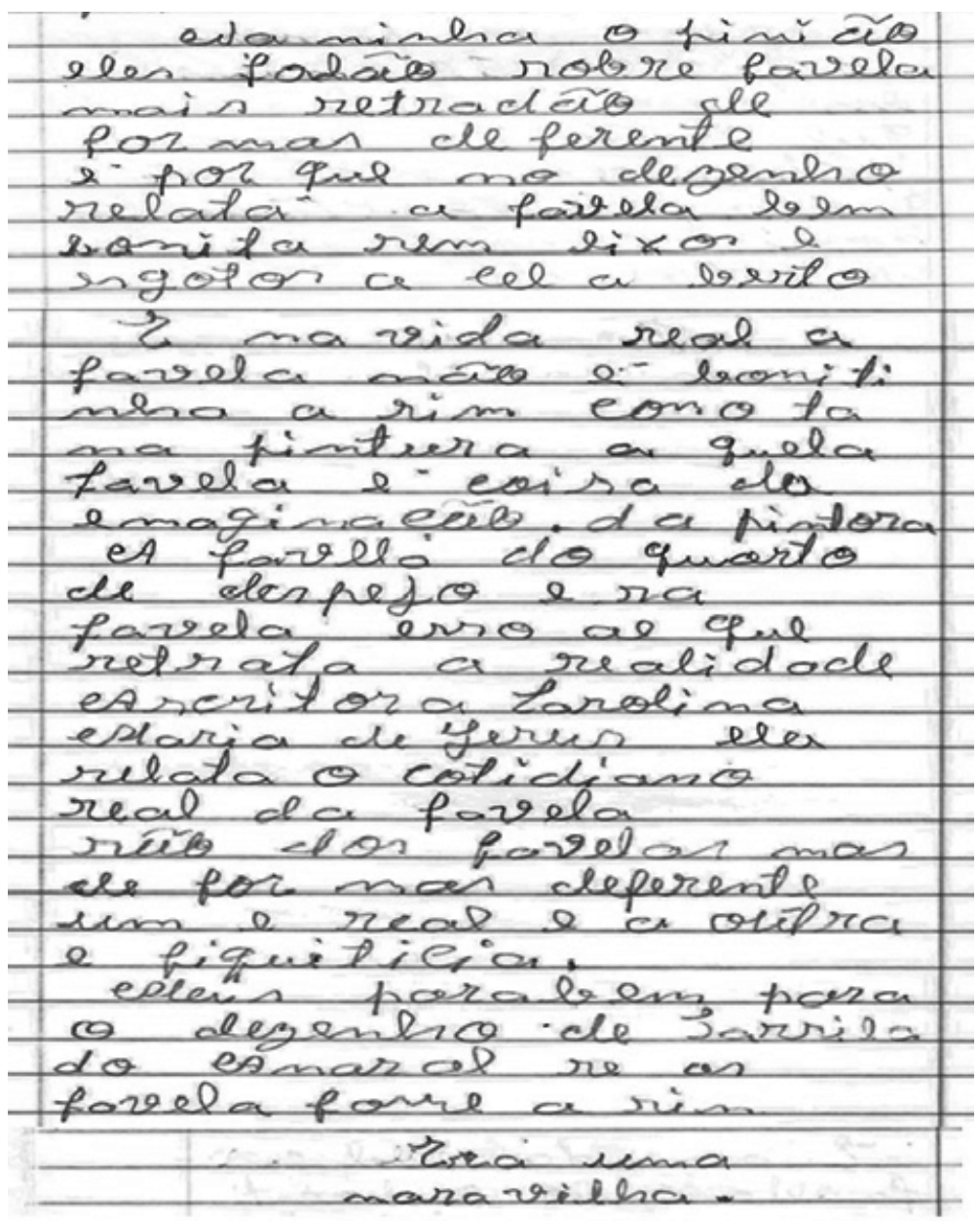

Fonte: Arquivo da professora de Língua Portuguesa do ciclo IV da EJA.

Em O3, percebemos o pleno atendimento à orientação, confrontando elementos da caracterização espacial para identificar as diferenças que fazem da obra de Tarsila do Amaral um retrato "fictício" da favela, enquanto a de Ca- rolina Maria de Jesus se constitui como "realidade". Para essa observação, O3 recorre a uma breve descrição de Morro da favela - "favela bem bonita, sem lixos e esgoto a céu aberto" - e a uma percepção pessoal de mundo que lhe permite 
afirmar que "na vida real a favela não é bonitinha assim".

Além disso, a colocação final expressa nitidamente uma apreciação da obra tarsiliana ao mesmo tempo em que reforça todo o percurso comparativo desenvolvido no registro. Portanto, dentro dos limites da construção linguística de
O3 - percebidos pelos desvios recorrentes do padrão de correção gramatical -, percebemos o que Buzzo descreve como uma "reflexão estruturada do leitor" estabelecida em uma "autêntica situação de comunicação entre leitor e autor" (2010, p. 17).

Figura 5 - Produção 12 correspondente ao nível de atendimento na terceira orientação

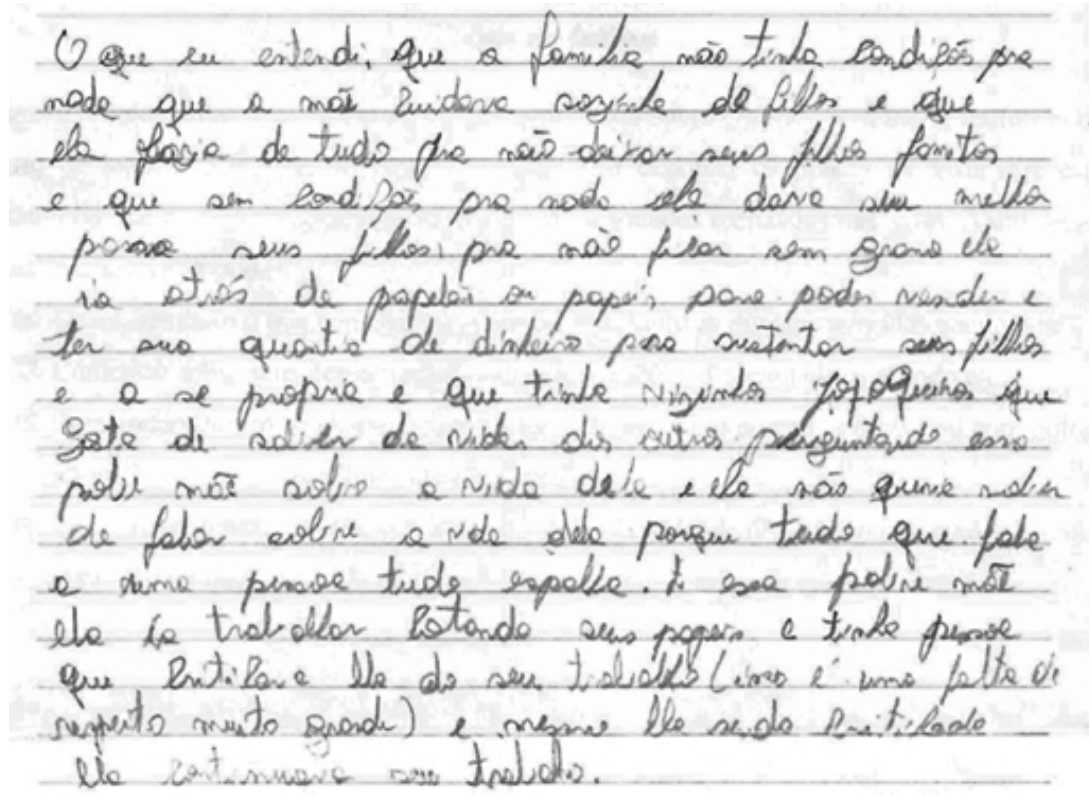

Fonte: Arquivo da professora de Língua Portuguesa do ciclo IV da EJA.

Quanto a I2, não se realiza qualquer cotejo de obras com Quarto de despejo. Entretanto, destacamos que essa segunda produção avança, ainda que timidamente, em relação à primeira do mesmo estudante, pois quando analisamos I1, no tocante à segunda orientação, apontamos que fora feito apenas um resumo de passagens da obra caroliniana, não havendo sequer colocações pessoais sobre $o$ texto. Agora, mesmo que não atendendo à terceira orientação, observamos em I2 um "eco subjetivo", como nomeia Langlade, já perto do final do registro: "(isso é uma falta de respeito muito grande)". Dessa forma, o letramento literário, com o avançar das etapas, leituras e discussões, ajudou na produção de um registro que inicia seu processo de transição para o gênero diário de leitura. 
Por fim, a quarta orientação - "transcrever trechos de Quarto de despejo ou de outras obras sobre as quais queira falar e usar como exemplos para seus comentários" - requer a articulação de um comentário ao excerto que o desencadeou, engendrando uma construção textual com alusões mais facilmente recuperáveis na leitura. Objetivamos suscitar o emprego de construções referenciais na urdidura do texto, tendo sido a orientação mais direta quanto a um funcionamento linguístico.

Ressaltamos que para a escrita de diários de leitura não é obrigatória a citação, muito menos comentada. É aceitável, por exemplo, a transcrição de trechos simplesmente pelo interesse, concordância ou encantamento que provocam. Sobre esse aspecto, Rouxel explica: "Por vezes as passagens copiadas são tão longas que compõem, no diário, uma espécie de antologia pessoal; às vezes esses extratos são apresentados sem comentários, pois, explica o leitor, o texto basta por si só" (2012, p. 277). Vejamos alguns exemplos a seguir, nas Figuras 6 e 7:

Figura 6 - Produção B1 correspondente ao nível de atendimento na quarta orientação

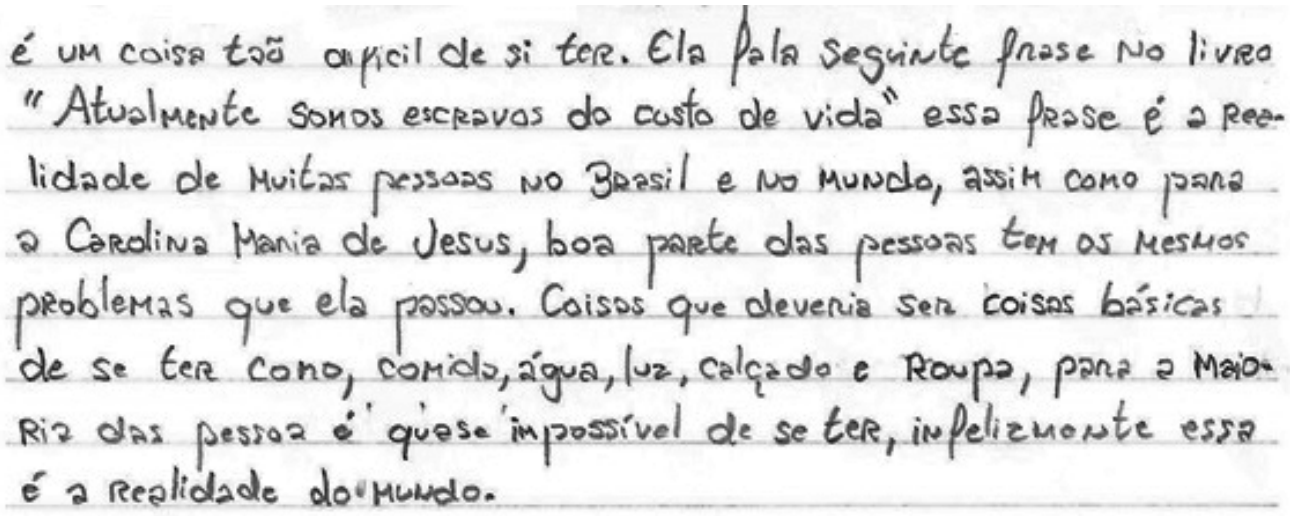

Fonte: Arquivo da professora de Língua Portuguesa do ciclo IV da EJA.

A produção B1 atende plenamente à orientação por meio da citação "Atualmente somos escravos do custo de vida", seguida de uma explanação acerca de sua validade no contemporâneo presente do sujeito leitor, autor do registro. Constituiu-se, nessa construção, o diálogo com o texto de uma maneira em que foi possível acompanhar a organização da reflexão. Machado salienta que a produção de diários de leitura "leva os alunos a desenvolverem, por meio da escrita, diferentes operações de linguagem que leitores maduros naturalmente realizam, quando se encontram em situação de leitura" (2005, p. 65). B1 se mostra como um exemplo da viabilidade dessa prática. 
Figura 7 - Produção E1 correspondente ao nível de atendimento na quarta orientação.

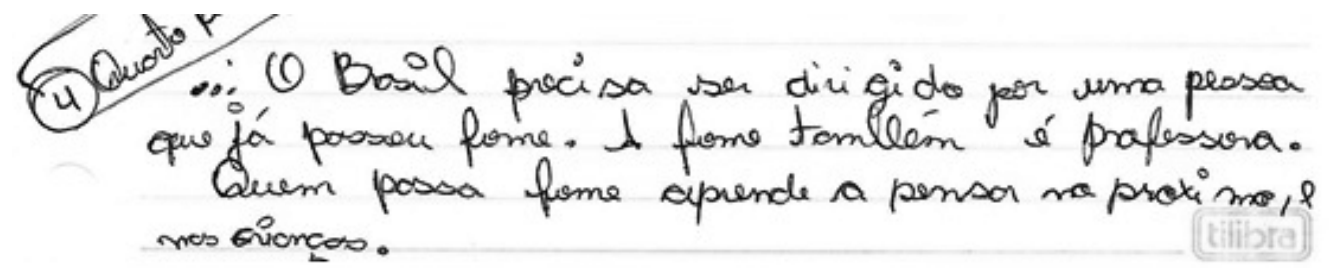

Fonte: Arquivo da professora de Língua Portuguesa do ciclo IV da EJA.

Por sua vez, E1 somente transcreve um trecho de Quarto de despejo, sem articulá-lo a nenhum comentário. No contexto do ciclo IV da EJA, o mais comum foram os comentários "urdidos de não ditos", que Rouxel aponta como "traços de leitura presentes nos diários íntimos dos adolescentes" (2012, p. 277). Aqui poderíamos conjecturar essa contextura de "não ditos" em torno de uma aprovação ou discordância quanto ao conteúdo da citação, porém qualquer dessas possibilidades - ou outras não aventadas - não encontra esteio no texto do registro. Assim, E1 atende parcialmente à quarta orientação.

As produções típicas do ciclo IV da EJA para a quarta orientação, contudo, não transcreviam trechos de obras, articulados ou não a comentários. Ademais, a separação das orientações em quatro categorias consistiu em uma sistematização, mormente, para fins de análise, visto que imbricações entre as orientações 1 e 2 , bem como entre 3 e 4 , se mostraram constantes nas produções dos estudantes. Essa constatação não nulifica a prática realizada, pois as orientações permitiram a participação de estudantes afastados da escrita por razões que iam desde desinteresse até inassiduidade às aulas, passando por déficit nos processos de alfabetização e letramento.

Além disso, os sujeitos da EJA constroem conhecimentos também fora do contexto escolar, todos são falantes nativos da língua, embora nem todos se expressem dentro dos padrões de correção linguística, oralmente ou por escrito. Por meio da compilação de trechos dos diários de leitura para análise, por exemplo, tornamos manifestos graus variados de escrita, apreciação e apreensão das obras, algo compreensível e esperado, dada a heterogeneidade nessa modalidade de ensino. Demonstrou-se patente, nesse sentido, a transposição da oralidade para a escrita em diversos registros, contudo, entendemos que exigir correção gramatical quando buscamos instigar a expressão de pontos vista reflexivos e críticos, por si só, não aperfeiçoaria a escrita.

Lidamos, afinal, com uma obra caroliniana cujos desvios da norma gramatical da língua não anulam os aspectos estético e crítico interpretados em sua escrita. Seria, por conseguinte, incongruente que o foco de nossa análise se voltasse para 
a correção linguística nos diários de leitura. Recaiu, antes, sobre a experiência da leitura, ela mesma, com as reflexões, imaginações e oscilações próprias da interação com os textos.

\section{Considerações finais}

A analogia de gênero que o diário de leitura divide com a obra caroliniana se mostrou como uma maneira de estimular a expressão de pontos de vista tanto mais pessoais quanto mais críticos e reflexivos, tendo em vista que esses aspectos são facilmente identificáveis na escrita de Carolina Maria de Jesus. Nesse sentido, a escrita de diários de leitura revelou seu potencial como instrumento sinalizador da expressão subjetiva do sujeito leitor na construção de sentidos para os textos.

Em nosso propósito de promover a leitura literária no ciclo IV da EJA, deparamo-nos com diversas manifestações de respostas dos estudantes no diálogo com as obras complementares trabalhadas com Quarto de despejo, e com a própria obra caroliniana, evidentemente. Percebemos consonâncias, dissonâncias, identificações, distanciamentos etc. Todas essas respostas, acreditamos, se configuraram como possibilidade de os estudantes desenvolverem sua escrita de invenção, como a denomina Annie Rouxel (2012), isto é, escritas que reagem aos textos apropriando-se deles, de sua linguagem. Escritas, enfim, de construção de sentidos para os textos e a partir dos textos.
No ciclo IV da EJA, tais escritas consistiram em variados graus de apreensão da leitura literária. Nessa modalidade de ensino, afinal, encontramos um público escolar já reconhecido como heterogêneo, para o qual procedimentos metodológicos e pedagógicos convencionais, próprios para os níveis de ensino "regular", são desprovidos de significação - por exemplo, o livro didático não contempla níveis de alfabetização e letramento díspares; produções textuais de gêneros como o artigo de opinião ou a resenha atraem as pessoas mais jovens, interessadas em seguir estudos de nível superior, mas não as mais velhas, em geral, mais receptivas a dinâmicas de socialização.

Dessa maneira, a elaboração de uma sequência básica de letramento literário se apresentou como uma possibilidade de efetivar o contato com a literatura, incentivando a predileção por ela. Nesse trajeto, foi preciso repensar o espaço e a função do texto literário na sala de aula, de modo geral, bem como na EJA, especificamente. Assim, para dimensionarmos a efetividade do processo de letramento literário realizado, consideramos os aspectos quantitativo e qualitativo relativos à sua concretização.

A participação dos estudantes somada a cada produção, individual ou em grupo, nos possibilitaram acompanhar a frequência nas atividades e o progresso no desenvolvimento de saberes acerca de Carolina Maria de Jesus e sua obra de estreia. Por sua vez, o conteúdo das produções nos permitiu observar o alcance do interesse despertado pela história 
de vida da escritora, a ampliação dos contextos de leitura para sua obra a partir dos textos complementares, além da reflexão direcionada a esses textos, à obra principal e ao cenário social brasileiro. As produções analisadas ilustram, nesse âmbito, construções de sentido elaboradas pelos estudantes com base na assimilação gradativamente mais crítica e relacional de seus repertórios sociocultural e literário.

Outro enfoque adotado, além da interação autor-obra-leitor, foi o estabelecimento de experiências coletivas de leitura e interpretação, seja na realização de atividades em grupo na etapa de intervalos - mais próximas das práticas docentes convencionais -, seja na de leitura ou de socialização dos registros - ambas ainda timidamente realizadas pelos estudantes, porém relevantes tanto para o aprofundamento na construção de sentidos quanto para a remodelação da escola e das aulas de língua portuguesa como espaço e momento de expressão de subjetividades.

\section{Journaux dans l'EJA: lecture littéraire de Le dépotoir, de Carolina Maria de Jesus}

\section{Résumé}

Ce travail résume une pratique pédagogique réalisée avec des groupes du cycle IV de l'Education des Jeunes et des Adultes (EJA) en 2017, dans une école publique de la capitale de Paraíba. Cette propo- sition répondait aux exigences du Programme de Maîtrise Professionnelle en Lettres, résultant en une Dissertation de Maîtrise et comprenant la réalisation d'une séquence élémentaire d'alphabétisation littéraire (COSSON, 2014), ainsi que l'observation et l'analyse de la production de journaux de lecture par les étudiants (MACHADO, 2005; ROUXEL, 2012). Avec la recherche et l'intervention pédagogique en question, on a essayé de promouvoir la lecture littéraire dans l'EJA au travers de Le dépotoir, de Carolina Maria de Jesus. L'ensemble des productions des élèves a démontré que l'exercice d'écriture de journaux de lecture peut développer l'expression de points de vue plus critiques et l'appréhension du langage littéraire, en mettant l'accent sur la subjectivité du lecteur.

Mots-clé: Lecture littéraire. Alphabétisation littéraire. Journaux de lecture. EJA. Le dépotoir.

\section{Notas}

1 Neste trabalho, empregamos a nomenclatura literatura marginal/periférica, adotando a opção conceitual de Jéssica Balbino (2016) acerca de uma movimentação artística recente no Brasil, do início dos anos 2000, marcada pela colaboração entre o escritor paulistano Ferréz e a revista Caros Amigos, e que resultou na publicação da coleção de revistas "Literatura Marginal”. Periférico, ainda segundo Balbino, deriva da eclosão de uma cena artística, igualmente recente, marcada pelos saraus literários nas periferias brasileiras. Assim, consideramos marginal/periférico o trabalho de Carolina Maria de Jesus, pois, mesmo publicada por uma grande editora já em sua estreia, não deixou de ocupar as margens do centro literário brasileiro. Além de os temas de sua escrita abordarem a vida na periferia de uma grande cidade. 
2 As especificidades da EJA são bem definidas por Marta Kohl de Oliveira (1999) e por Leôncio Soares (2011). Pensando no conjunto do público atendido na EJA e na estrutura dessa modalidade ensino, destacamos: heterogeneidade etária, de níveis de letramento e de experiências de vida dos estudantes; necessidade de formação docente especializada, de composição do material didático e do currículo voltados para a modalidade; organização de tempo e espaço adaptados para a escolarização; políticas de recreação e cuidado para os filhos de alunas da EJA, de alimentação e de transporte.

3 Rildo Cosson distingue dois tipos de atividades de leitura: a leitura ilustrada, "de fruição e deleite, voltada quase que exclusivamente para a inserção do aluno no mundo da escrita ou o manuseio livre de impressos, sendo esse o modo preferencial de uso do texto literário nos anos iniciais do ensino fundamental", e a leitura aplicada, que "se destina ao aprendizado de alguma coisa do qual o texto é veículo. Trata-se do modo dominante da leitura nos anos finais do ensino fundamental e daí por diante, mudando-se o grau de complexidade dos textos e os fins imediatos da leitura" (2015, p. 165).

4 Cada trecho dos diários de leitura aparece identificado por uma letra, correspondendo ao diário de um estudante, e também por um número, referente a cada um dos três registros realizados. Assim, trechos identificados como A1, A2 ou A3, por exemplo, correspondem ao diário do estudante A em sua primeira, segunda ou terceira escrita, respectivamente.

\section{Referências}

ABREU, Márcia. Cultura letrada: Literatura e leitura. São Paulo: Editora Unesp, 2006.

ANTUNES, Irandé. A leitura: de olho nas suas funções. In: _. Língua, texto e ensino: outra escola possível. São Paulo: Parábola Editorial, 2009, p. 185-206.

BALBINO, Jéssica. Pelas margens: vozes femininas na literatura periférica. Dissertação de Mestrado. Universidade Estadual de Campinas, Instituto de Estudos da Linguagem, 2016. Disponível em: http://repositorio. unicamp.br/jspui/handle/REPOSIP/321220. Acesso em 19 out. 2018.
BUZZO, Marina Gonçalves. O diário de leitura como artefato ou instrumento no trabalho docente.Revista l@el em (dis-)curso,v. 2, n. 1, p. 10-26, 2010. Disponível em: http:// revistas.pucsp.br/index.php/revlael/article/ view/1041/2565. Acesso em: 20 out. 2018.

CANDIDO, Antônio. O direito à literatura. In: _. Vários escritos. 5. ed. São Paulo/ Rio de Janeiro: Ouro sobre azul, 2011, p. 171-193.

CORONEL, Luciana Paiva. A censura ao direito de sonhar em Quarto de despejo, de Carolina Maria de Jesus. Estudos de Literatura Brasileira Contemporânea, n. 44, p. 271-288, jul./dez. 2014. Disponível em: http://periodicos.unb.br/index.php/estudos/ article/view/12517/8705. Acesso em: 19 out. 2018.

COSSON, Rildo. Letramento literário: teoria e prática. 2. ed. São Paulo: Contexto, 2014.

A prática da leitura literária na escola: mediação ou ensino? Nuances: estudos sobre Educação, Presidente Prudente/SP, v. 26, n. 3, set./dez. 2015, p. 161-173.

DALCASTAGNÈ, Regina. Para não ser trapo no mundo: as mulheres negras e a cidade na narrativa brasileira contemporânea. Estudos de Literatura Brasileira Contemporânea, $\mathrm{n}$. 44, p. 289-302, jul./dez. 2014. Disponível em: http://periodicos.unb.br/index.php/estudos/ article/view/12518/8706. Acesso em: 19 out. 2018.

DANTAS, Audálio. Prefácio: a atualidade do mundo de Carolina. In: JESUS, Carolina Maria de. Quarto de despejo: diário de uma favelada. 10. ed. São Paulo: Ática, 2014.

GOMES, Romeu. Análise e interpretação de dados de pesquisa qualitativa. In: MINAYO, Maria Cecília de Souza (Org.). Pesquisa social: teoria, método e criatividade. 28. ed. Petrópolis, RJ: Vozes, 2009, p. 79-108.

JESUS, Carolina Maria de. Quarto de despejo: diário de uma favelada. 10. ed. São Paulo: Ática, 2014. 
KLEIMAN, Ângela. Preciso "ensinar" o letramento? Não basta ensinar a ler e a escrever? Campinas: Cefiel-Unicamp/MEC, 2005.

LAJOLO, Marisa. Do mundo da leitura para a leitura do mundo. São Paulo: Ática, 1993.

LANGLADE, Gérard. O sujeito leitor, autor da singularidade da obra. In: ROUXEL, Annie; LANGLADE, Gérard; REZENDE, Neide Luzia de (Org.). Leitura subjetiva e ensino de literatura. Trad. Amaury C. Moraes et al. São Paulo: Alameda, 2013, p. 25-38.

MACHADO, Anna Rachel. Diários de leituras: a construção de diferentes diálogos na sala de aula. Linha d'Água, n. 18, 2005, p. 61-74. Disponível em: http://www.revistas. usp.br/linhadagua/article/view/37279. Acesso em: 20 out. 2018.

OLIVEIRA, Marta Kohl de. Jovens e adultos como sujeitos de conhecimento e aprendizagem. Revista Brasileira de Educação, n. 12, 1999, p. 59-73. Disponível em: http://anped. tempsite.ws/novo_portal/rbe/rbedigital/ RBDE12/RBDE12_06_MARTA_KOHL_DE_ OLIVEIRA.pdf. Acesso em: 20 out. 2018.

PAULINO, Graça. Letramento literário: por vielas e alamedas. Revista da Faced / UFBA, Salvador, n. 5, 2001, p. 117-125. Disponível em: https:/portalseer.ufba.br/index.php/ entreideias/article/view/2842/2018. Acesso em: 20 out. 2018.
Formação de leitores: a questão dos cânones literários. Revista Portuguesa de Educação, n. 17(1), 2004, p. 47-62. Disponível em: http://www.redalyc.org/articulo. oa?id=37417104. Acesso em: 20 out. 2018.

POSSENTI, Sírio. Por que (não) ensinar gramática na escola. Campinas: Mercado das Letras, 1996.

ROUXEL, Annie. Práticas de leitura: quais rumos para favorecer a expressão do sujeito leitor? Cadernos de Pesquisa, v. 42, n. 145, p. 272-283, jan./abr. 2012. Disponível em: http://publicacoes.fcc.org.br/ojs/index.php/ cp/article/view/90. Acesso em: 20 out. 2018.

SOARES, Leôncio. As especificidades na formação do educador de jovens e adultos: um estudo sobre propostas de EJA. Educ. rev., Belo Horizonte, v. 27, n. 2, p. 303-322, ago. 2011. Disponível em: http://www.scielo.br/scielo.php?script $=$ sci_arttext\&pid $=\mathrm{S} 0102$ $-46982011000200014 \& \operatorname{lng}=\mathrm{en} \& \mathrm{nrm}=\mathrm{iso}$. Acesso em: 19 out. 2018.

SOUZA, Germana Henrique Pereira de. Carolina Maria de Jesus: o estranho diário da escritora vira lata. Vinhedo-SP: Editora Horizonte, 2012. 